University of Nebraska - Lincoln

DigitalCommons@University of Nebraska - Lincoln

USDA National Wildlife Research Center - Staff Publications
U.S. Department of Agriculture: Animal and Plant Health Inspection Service

2010

\title{
An Evaluation of Diazacon as a Potential Contraceptive in Non- Native Rose-Ringed Parakeets
}

\author{
Mark Lambert \\ Food and Environment Research Agency, United Kingdom \\ Giovanna Massel \\ Food and Environment Research Agency, United Kingdom \\ Christi Yoder \\ USDA-APHIS-Wildlife Services \\ David Cowan \\ Food and Environment Research Agency, United Kingdom
}

Follow this and additional works at: https://digitalcommons.unl.edu/icwdm_usdanwrc

Part of the Environmental Sciences Commons

Lambert, Mark; Massel, Giovanna; Yoder, Christi; and Cowan, David, "An Evaluation of Diazacon as a Potential Contraceptive in Non-Native Rose-Ringed Parakeets" (2010). USDA National Wildlife Research Center - Staff Publications. 934.

https://digitalcommons.unl.edu/icwdm_usdanwrc/934

This Article is brought to you for free and open access by the U.S. Department of Agriculture: Animal and Plant Health Inspection Service at DigitalCommons@University of Nebraska - Lincoln. It has been accepted for inclusion in USDA National Wildlife Research Center - Staff Publications by an authorized administrator of DigitalCommons@University of Nebraska - Lincoln. 


\title{
An Evaluation of Diazacon as a Potential Contraceptive in Non-Native Rose-Ringed Parakeets
}

\author{
MARK S. LAMBERT, ${ }^{1}$ The Food and Environment Research Agency, Sand Hutton, York YO41 1LZ, United Kingdom \\ GIOVANNA MASSEI, The Food and Environment Research Agency, Sand Hutton, York YO41 1LZ, United Kingdom \\ CHRISTI A. YODER, National Wildlife Research Center, 4101 Laporte Avenue, Fort Collins, CO 80521-2154, USA \\ DAVID P. COWAN, The Food and Environment Research Agency, Sand Hutton, York YO41 1LZ, United Kingdom
}

\begin{abstract}
Rose-ringed parakeets (Psittacula krameri) have become widely established outside their native range through accidental or deliberate release. Potential economic impacts on agriculture, conservation concerns, and mixed public opinion regarding the species have highlighted the need to develop effective but humane management options. Fertility control might provide such a solution if a safe and environmentally benign contraceptive was available. The chemical 20,25-diazacholesterol dihydrochloride (diazacon) has previously been used to reduce reproductive output in avian species through reduction of blood cholesterol and cholesterol-dependent reproductive hormones. We orally dosed captive rose-ringed parakeets with a solution of either $9 \mathrm{mg} / \mathrm{kg}$ or $18 \mathrm{mg} / \mathrm{kg}$ of diazacon for up to 10 days and found that a dose of $18 \mathrm{mg} / \mathrm{kg}$ for 10 days temporarily reduced blood cholesterol levels with no adverse side effects. We evaluated this dose level in a captive population in semi-natural conditions during the 2008 breeding season and found a significant decrease in fertility. We concluded that diazacon has potential for fertility control in this species if a suitable formulation and delivery system is developed for free-living populations.
\end{abstract}

KEY WORDS breeding success, cholesterol, fertility control, invasive species, parrots, Psittacula krameri.

Human-wildlife conflicts are rarely resolved without some degree of controversy. Often the need to control problem wildlife, or manage desirable species, has to be balanced against the need to manage populations in a way that meets with acceptance from stakeholders such as local authorities, conservation bodies, and the public (Messmer et al. 1997, Stout et al. 1997, Marshall et al. 2007). Rose-ringed parakeets (Psittacula krameri), also known as ring-necked parakeets, are native to central Africa and Asia but through accidental and deliberate release, populations are now established in Europe, Japan, and the United States (Lever 2005). As an invasive non-native species, the rose-ringed parakeet has raised conservation concerns, because its early breeding season and preference for established nest cavities places it in potential conflict with native cavity-nesting birds (Lever 2005, Strubbe and Matthysen 2007). In their native range, rose-ringed parakeets are considered a serious agricultural pest, particularly of fruit (Babu and Muthukrishnan 1987, Patel et al. 2002); hence, their population expansion is also of economic interest. In Europe, free-living populations have started to expand recently, but they are currently concentrated in urban areas. In urban areas, roseringed parakeets are sometimes regarded as a colorful addition to the native fauna, which has resulted in conflicting views on how they should be managed. As an invasive species that may have negative impacts on native fauna, rose-ringed parakeets should be removed. However, the species is now recognized as established in some countries including the United Kingdom, and it is unlikely that full-scale eradication would be fully supported by the general public. Nonlethal techniques might offer a middleground solution with potential for long-term population

${ }^{1}$ E-mail: mark.lambert@fera.gsi.gov.uk management, provided they are effective, humane, and environmentally friendly. Fertility control is one such technique that appears to meet with public acceptance (Messmer et al. 1997, Stout et al. 1997).

Several wildlife contraceptives or fertility control agents have been developed in recent years for situations where lethal control would be neither desirable nor possible (Miller and Fagerstone 2000). Originally developed as a cholesterol inhibitor in humans, diazacon (20,25-diazacholesterol dihydrochloride) can potentially decrease reproduction in birds through reduction of cholesterol-dependent reproductive hormone levels (Yoder et al. 2004). Diazacon has been evaluated against several avian species and, although early work gave conflicting results and highlighted some possible welfare issues (Wofford and Elder 1967, Fringer and Granett 1970, Sturtevant and Wentworth 1970, Lacombe et al. 1987), recent studies have shown that, with the right dose, diazacon can act as a reproductive inhibitor in monk parakeets (Myiopsitta monachus) without adverse effects (Yoder et al. 2007, Avery et al. 2008).

We aimed to test effectiveness and potential side effects of diazacon in captive rose-ringed parakeets and to monitor the effect on reproduction in a semi-natural environment. We also monitored birds for potential side effects and other health and welfare implications. Specifically, we tested whether blood cholesterol levels were reduced in birds orally dosed with diazacon compared to controls and whether reproductive output was reduced.

\section{METHODS}

\section{Oral Dosing}

We obtained 13 adult rose-ringed parakeets from registered United Kingdom breeders in June and July 2005 and housed them in indoor aviaries measuring $2.5 \times 1.3 \times 2.5 \mathrm{~m}$ 
(length $\times$ width $\times$ ht) at the Food and Environment Research Agency, York, United Kingdom. Artificial lighting followed the natural day-night cycle, humidity was 47$80 \%$, and we maintained temperature at $16^{\circ} \mathrm{C}$ (range $\pm 2^{\circ}$ C). In March 2006 we habituated birds to handling and dosing for 5 days. During the habituation phase, we captured each bird in turn using a fine-mesh long-handled net and fed it $0.5 \mathrm{~mL}$ of jam and water mixture from a plastic syringe (without needle). On the final day of habituation we weighed all birds to provide a baseline weight for subsequent health monitoring and to allow calculation of an accurate individual dose by weight. We also took a pretrial blood sample of $0.4 \mathrm{~mL}$ from the jugular vein of each bird. We removed all food from the aviaries 6 hours prior to blood sampling to stabilize blood cholesterol. We then randomly allocated birds to treatment $(n=8)$ and control $(n=5)$ groups. On each of the next 5 days, each bird in the treated group received an oral dose of $9 \mathrm{mg} / \mathrm{kg}$ diazacon (trial 1) in $0.5 \mathrm{~mL}$ de-ionized water, half the dose of diazacon found to be effective against nesting monk parakeets in captivity (Yoder et al. 2007). Control birds received $0.5 \mathrm{~mL}$ de-ionized water on each of the 5 days.

We visually assessed condition of each bird twice daily during dosing and the following 2 weeks, daily for the next 4 weeks, and then every other day for a further 7 weeks using a scale of 1-3 (where 1 indicated a substantial change, 2 a slight but discernable change, and 3 no change) for the following parameters: 1) condition of feathers (sleeked, fluffed, or normal), 2) reaction (response to human presence), and 3) awareness (alert or lethargic). We weighed birds once each week for 14 weeks postdosing. We took further blood samples on days 8, 15, 29, 43, 71, and 99 (day 1 was the first dosing day). We measured food consumption for each pair each day during the habituation and dosing period and every day for 14 weeks postdosing and adjusted consumption for body weight.

We centrifuged blood samples for 5 minutes at 10,000 revolutions/minute (rpm), followed by 10 minutes at 14,000 rpm within 1 hour of sampling. We then drew the supernatant off each sample and froze it at $-10^{\circ} \mathrm{C}$. We analyzed blood plasma for desmosterol (a precursor to cholesterol) and cholesterol concentrations by high-performance liquid chromatography using the method reported by Johnston et al. (2003).

We obtained 18 other birds in August 2007 and repeated the trial using $18 \mathrm{mg} / \mathrm{kg}$ (trial 2). Dosing continued for 10 days (in 2 5-day blocks), with 10 treated birds and 8 controls. We obtained blood samples on days 15, 29, 43, 71, and 99 and monitored food consumption for 10 weeks postdosing; otherwise, the protocol followed our methods for the $9-\mathrm{mg} / \mathrm{kg}$ trial.

\section{Reproductive Study}

In January 2008, we randomly allocated 23 pairs of roseringed parakeets from an outdoor breeding colony established in 2005 (Lambert et al. 2009) to either treatment ( $n$ $=12$ pairs) or control groups ( $n=11$ pairs). We housed the birds in outdoor aviaries $(7 \times 3 \times 2 \mathrm{~m})$ with one pair per aviary. We fed both groups of birds commercial seed mixture for parrots ad libitum. We provided fresh fruit and water daily and offered millet and peanuts once per week. We habituated all birds to the dosing procedure (as in previous trials) for 5 days beginning 14 January 2008. For the following 2 weeks, we gave all birds ( $\mathrm{M}$ and $\mathrm{F}$ ) in the treated group $18 \mathrm{mg} / \mathrm{kg}$ (trial 3) diazacon in $0.5 \mathrm{~mL}$ distilled water each day for 10 days (in 2 -day blocks) as in the second oral dosing trial. We gave control birds $0.5 \mathrm{~mL}$ distilled water each day for the same 10 days. At the end of the 2-week dosing period (1 Feb 2008) we fixed wooden nest boxes $(32 \times 32 \times 64 \mathrm{~cm})$ to the aviary walls. Thereafter, we visually checked birds each day to monitor any potential side effects and checked nest boxes twice weekly for presence of eggs.

During the main activity periods (determined by a pilot trial the previous year as $3 \mathrm{hr}$ after sunrise and $3 \mathrm{hr}$ before sunset) we observed behavior of each treated and control pair twice every fortnight (once in the morning and once in the afternoon) using a 30-minute instantaneous scan sample at 2-minute intervals (Altmann 1974). Observations continued until first clutches had been completed or it was clear that eggs would not be laid. During each 30-minute observation session (which was preceded by a 10 -min wait to accustom birds to presence of the observer) we recorded behavior of each bird every 2 minutes and recorded interactions between birds as either positive (directed toward the partner) or negative (directed away from the partner).

We removed eggs when the first clutch was completed and candled them using a low-intensity light source to check for fertility as indicated by development of the embryo and associated blood vessels. We allowed birds to produce a second clutch to determine whether treated birds could produce a further viable clutch if the first was infertile. We allowed birds to incubate and hatch their second clutch. We observed 2 pairs (one treated and one control) with infertile clutches to determine the length of time females attempted to incubate infertile eggs.

\section{Data Analysis}

For the first 2 trials, we examined the effect of date, treatment, sex, and their interaction on concentration of cholesterol using residual maximum likelihood (REML) analysis. Residual maximum-likelihood techniques are particularly useful where sample sizes are unequal, because the approach avoids some of the problems of biased variance estimates found with standard maximum-likelihood estimation and, thus, can be routinely applied to unbalanced data (Brown and Kempton 1994). We compared bird weights between groups at the start and end of the trial using one-way analysis of variance (ANOVA). We compared food consumption between groups using repeatedmeasures ANOVA with bird weight added as a covariate. For trial 3, we examined the effect of treatment on total number of eggs and number of fertile eggs produced, and the effect of treatment, sex, and their interaction on behavior, using REML analyses. We $\log _{10}(\mathrm{~N}+1)$ transformed behavior data for normality. We used Genstat 


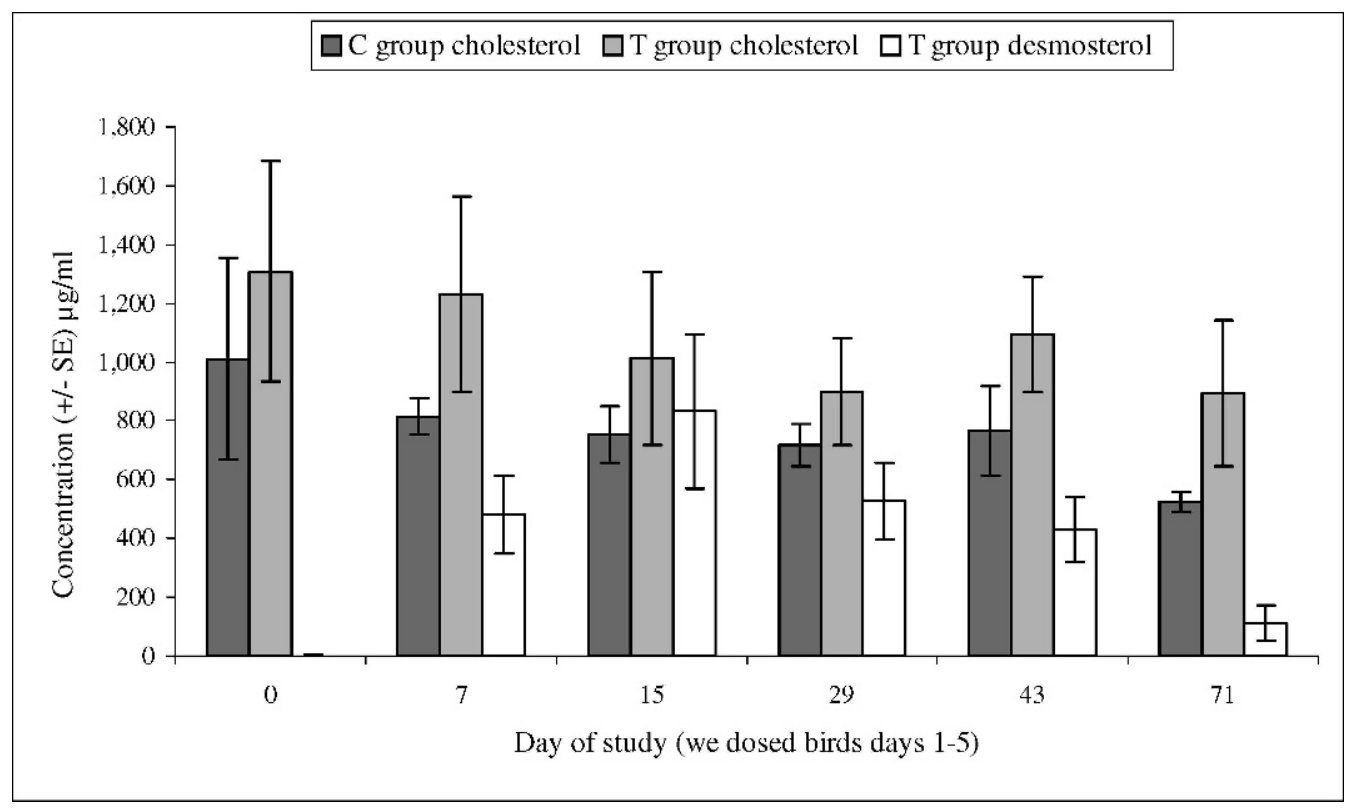

Figure 1. Blood cholesterol and desmosterol levels in captive rose-ringed parakeets following dosing with water $(\mathrm{C}=\mathrm{control}, n=7)$ or $9 \mathrm{mg} / \mathrm{kg}$ diazacon $(\mathrm{T}=$ treated, $n=5)$ for 5 days (trial 1), Yorkshire, United Kingdom, March-July 2007. Data are means \pm standard error, day $0=$ pretrial data. Mean desmosterol in control birds remained $<5 \mu \mathrm{g} / \mathrm{mL}$.

9 (VSN International Ltd., Hemel Hempstead, United Kingdom) for the repeated-measures ANOVA and SPSS 15.0 (SPSS Inc., Chicago, IL) for all other statistical analyses.

\section{RESULTS}

\section{Oral Dosing}

Following dosing with $9 \mathrm{mg} / \mathrm{kg}$, mean cholesterol in treated birds declined from 1,309 ( $\pm 375 \mathrm{SE}) \mu \mathrm{g} / \mathrm{mL}$ to $893( \pm 248$ SE) $\mu \mathrm{g} / \mathrm{mL}$ by day 71 (Fig. 1). There was also a decline in mean cholesterol in the control group over the same period, from $1,011( \pm 343 \mathrm{SE}) \mu \mathrm{g} / \mathrm{mL}$ to $524( \pm 35 \mathrm{SE}) \mu \mathrm{g} / \mathrm{mL}$. Changes in cholesterol levels within groups between sampling dates were not significant $\left(F_{5,55}=0.594, P=\right.$ $0.705)$. Cholesterol was lower in control birds $\left(F_{1,55}=\right.$ 4.200, $P=0.045)$, but there was no interaction between sampling date and group $\left(F_{5,55}=0.069, P=0.997\right)$. Cholesterol levels between males and females did not differ $\left(F_{1,55}=3.669, P=0.061\right)$. Desmosterol increased in treated birds from $<5 \mu \mathrm{g} / \mathrm{mL}$ to a peak of $832( \pm 264 \mathrm{SE})$ $\mu \mathrm{g} / \mathrm{mL}$ by day 15 . Mean desmosterol in control birds remained at $<5 \mu \mathrm{g} / \mathrm{mL}$ throughout the trial.

Following dosing with $18 \mathrm{mg} / \mathrm{kg}$, mean cholesterol levels in treated birds declined by $67.6 \%$ of the pretreatment level, from $729( \pm 57 \mathrm{SE}) \mu \mathrm{g} / \mathrm{mL}$ at day 0 to $236( \pm 20 \mathrm{SE}) \mu \mathrm{g} /$ $\mathrm{mL}$ at day 43 postdosing (Fig. 2). Cholesterol increased between day 43 and 71, and returned to near pretreatment levels by day 99. Cholesterol in control birds declined by $45.5 \%$, from $854( \pm 89 \mathrm{SE}) \mu \mathrm{g} / \mathrm{mL}$ at day 0 to $466( \pm 37$ $\mathrm{SE}) \mu \mathrm{g} / \mathrm{mL}$ at day 29 . There was a difference in cholesterol levels between treated and control groups $\left(F_{1,84}=99.717, P\right.$ $<0.001)$ and changes in cholesterol between sampling dates within groups $\left(F_{5,84}=33.272, P<0.001\right)$, but there was no interaction between sampling date and group $\left(F_{5,84}=\right.$
1.732, $P=0.136)$. Cholesterol levels between males and females did not differ $\left(F_{1,84}=0.516, P=0.474\right)$. Mean desmosterol increased in treated birds from $0 \mu \mathrm{g} / \mathrm{mL}$ to $\leq 458( \pm 26 \mathrm{SE}) \mu \mathrm{g} / \mathrm{mL}$ by day 71 . We did not detect desmosterol in control birds.

One treated male bird died during trial 1 and one control male died during trial 2, both birds during or shortly after the blood-sampling procedure. Otherwise, visual assessments of condition, reaction, and awareness did not reveal any signs of stress or significant changes in condition of the birds during or following dosing. Overall food consumption for treated birds (trial 2) was not different than that of control birds $\left(F_{1,6}=0.73, P=0.426\right)$. However, there was a time effect $\left(F_{47,328}=4.07, P<0.001\right)$ and a time $\times$ group interaction $\left(F_{47,328}=2.80, P<0.001\right)$ indicating a temporary elevation in food intake for treated birds following dosing (Fig. 3). During the trial, treated birds gained an average $5.1 \%$ body weight compared to $1.3 \%$ for control birds, although there was no difference in body weight between treated and control groups at the beginning $\left(F_{1,16}=0.42, P=0.53\right)$ or at the end of the trial $\left(F_{1,15}=\right.$ $1.39, P=0.26)$.

\section{Reproductive Study}

We found the first egg from control birds on 25 February 2008 and the first egg from treated birds on 14 March. Average time from the start of the trial to first egg was longer for treated birds $(68.9 \pm 3.5[\mathrm{SE}]$ days $)$ than for control birds (58.7 \pm 3.8 days; $P=0.033, t=1.965$, df $=$ 17; one-tailed $t$-test). Number of eggs produced (Fig. 4) did not differ between groups $\left(F_{1,43}=1.809, P=0.186\right)$ or clutches $\left(F_{1,43}=3.083, P=0.086\right)$ and there was no interaction between group $\times$ clutch $\left(F_{1,43}=0.006, P=\right.$ 0.940). However, treated birds produced fewer fertile eggs 


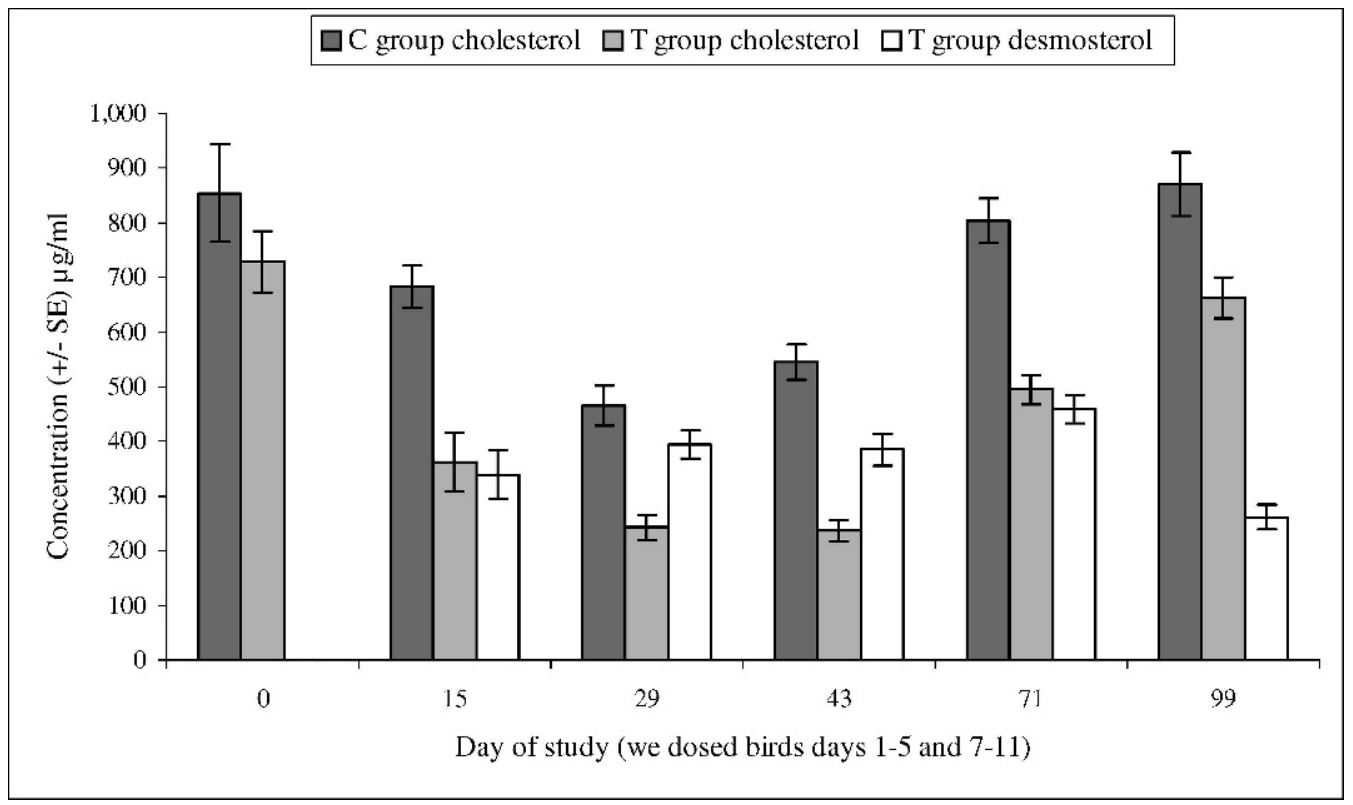

Figure 2. Blood cholesterol and desmosterol levels in captive rose-ringed parakeets following dosing with water $(\mathrm{C}=\operatorname{control}, n=10) \mathrm{or} 18 \mathrm{mg} / \mathrm{kg}$ diazacon $(\mathrm{T}=$ treated, $n=5)$ for 10 days (trial 2), Yorkshire, United Kingdom, October 2007-January 2008. Data are means \pm standard error; day $0=$ pretrial data. We did not detect desmosterol in control birds.

than did control birds $\left(P=0.013, F_{1,43}=6.748\right)$ with no difference between clutches $\left(F_{1,43}=1.467, P=0.233\right)$ or interaction between clutch $\times$ group $\left(F_{1,43}=0.018, P=\right.$ 0.895). First clutches were completed by mid-May 2008 (week 17 in Fig. 4), when 10/11 control pairs and 9/12 treated pairs produced 44 and 37 eggs, respectively. Treated birds produced 15 fertile eggs at their first attempt, an average of 1.25 ( $\pm 0.49 \mathrm{SE})$ eggs/pair within the population. Control birds produced 30 fertile eggs, an average of 2.73
$( \pm 0.52 \mathrm{SE})$ eggs/pair within the population. This disparity represents a reduction of $54.2 \%$ fertile eggs/pair at the population level. Nine out of 10 first clutches from control birds contained $\geq 1$ fertile egg; however, only 5/9 first clutches from treated birds contained $\geq 1$ fertile egg. Hence only $5 / 12$ treated pairs produced fertile eggs compared to $9 /$ 11 control pairs. Second clutches were completed by the end of June with 31 eggs from 7/11 controls and 24 eggs from 8/ 12 treated pairs. At their second attempt, 3 pairs of treated

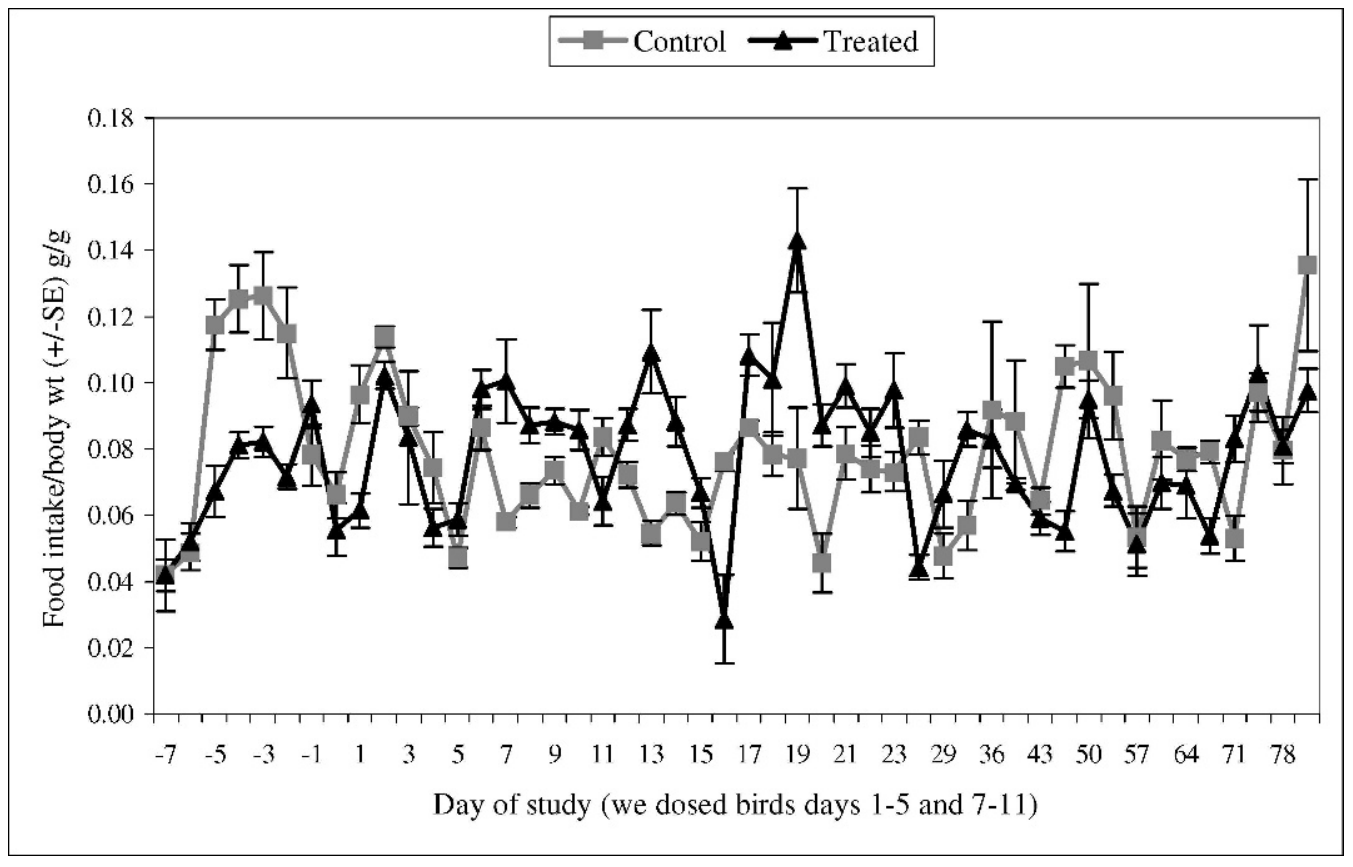

Figure 3. Food consumption in captive rose-ringed parakeets following dosing with water (control) or $18 \mathrm{mg} / \mathrm{kg}$ diazacon (treated) for $10 \mathrm{days}$ (trial 2), Yorkshire, United Kingdom, October 2007-January 2008. 


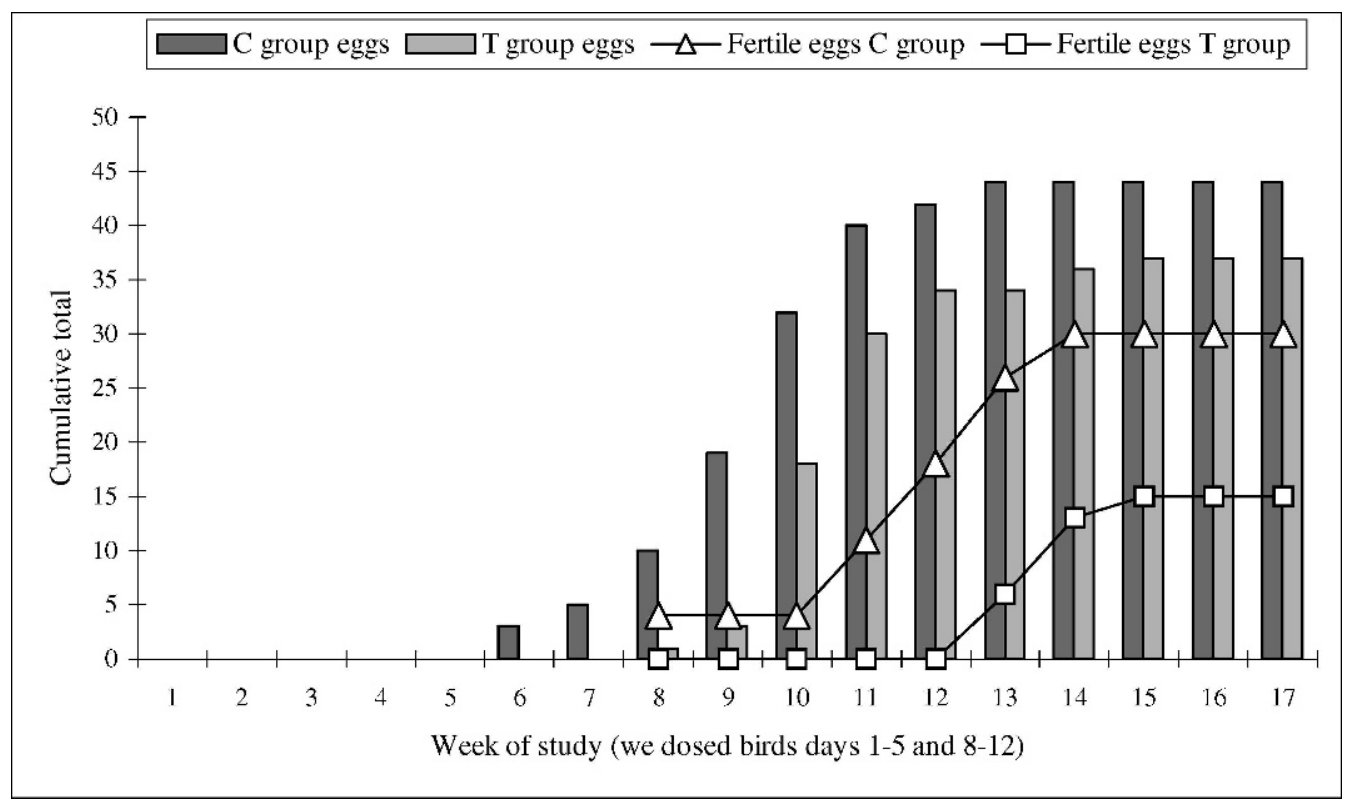

Figure 4. Eggs laid by captive rose-ringed parakeets (first clutch) following dosing with water $(\mathrm{C}=$ control, $n=11 \mathrm{pairs})$ or $18 \mathrm{mg} / \mathrm{kg}$ diazacon $(\mathrm{T}=$ treated, $n=12$ pairs) for 10 days (trial 3), Yorkshire, United Kingdom, February-June 2008. We provided nest boxes on the last day of dosing (1 Feb 2008) and checked them twice weekly thereafter. We removed and candled eggs to check fertility when the clutch was complete.

birds produced 8 fertile eggs, an average of $0.67( \pm 0.65 \mathrm{SE})$ eggs/pair within the population. Five pairs of control birds produced 22 fertile eggs, an average of $2.00( \pm 0.75 \mathrm{SE})$ eggs/pair within the population. This disparity represents a reduction of $66.5 \%$ fertile eggs/pair. Control birds hatched 12 second clutch eggs; treated birds hatched 6 .

We observed birds for 128 hours between treatment and completion of first clutch, an average of 177 observations/ bird at 2-minute intervals (Table 1). Number of positive interactions was higher for males than females $\left(F_{1,227}=\right.$ $10.264, P=0.002)$, which appeared to be mainly due to a peak in positive interactions from treated males toward their partners during weeks 9 and 10 (Fig. 5a). Differences between treatment groups $\left(F_{1,227}=1.212, P=0.272\right)$ and the interaction between sex and treatment group $\left(F_{1,227}=\right.$ 2.142, $P=0.145)$ were not significant. A corresponding peak in negative interactions from female birds accompanied the peak in positive interactions from male birds (Fig. 5b), but there was no difference between sexes $\left(F_{1,223}=1.300, P\right.$ $=0.256)$, treatment group $\left(F_{1,223}=1.604, P=0.207\right)$, or interaction between sex and treatment group $\left(F_{1,223}=\right.$ $0.549, P=0.460)$ for negative interactions. Treated birds spent a higher proportion of time sleeping (Fig. $5 \mathrm{c}$ ) than did control birds $\left(F_{1,214}=26.836, P=0.000\right)$ but there was no difference between sexes $\left(F_{1,214}=1.388, P=0.240\right)$ or interaction between sex and treatment $\left(F_{1,214}=1.785, P=\right.$ $0.183)$. The delay in egg laying seen in treated birds was reflected in delayed nesting behavior (Fig. 5d), although treated and control birds spent the same proportion of time in the nest box overall. Females spent more time in the nest box than did males $\left(F_{1,147}=29.02, P=0.000\right)$. For the 2 clutches with no fertile eggs that we observed to determine length of incubation period, females continued to incubate the eggs for $\geq 46$ days after the first egg was laid, although one of the females may have sat on infertile eggs for up to 60 days before she began to eject them from the nest. Two treated females and 2 control males died during the reproductive study. Postmortem examinations found no evidence that these deaths were treatment-related. We conducted our study under a United Kingdom Home Office license, in accordance with the Animals Act (Scientific Procedures) 1986 and subject to an internal ethical review process.

\section{DISCUSSION}

We found that a dose of $18 \mathrm{mg} / \mathrm{kg}$ diazacon reduced blood cholesterol in rose-ringed parakeets, and subsequently the proportion of fertile eggs produced, without adverse side effects. For the $9-\mathrm{mg} / \mathrm{kg}$ trial, cholesterol in the treated group was higher than in controls, because by chance the treated birds appeared to have higher baseline levels than did controls. We could not control for the difference in baseline cholesterol levels without reallocating groups on the basis of their pretreatment cholesterol levels. Dosing with $9 \mathrm{mg} / \mathrm{kg}$ diazacon for 5 days did not appear to affect blood cholesterol levels, because statistically, cholesterol levels in treated birds did not change among sampling dates. There did, however, appear to be some indications of a weak (but insignificant) experimental effect at this dose level; by 4 weeks postdosing (day 29), cholesterol in treated birds declined, reducing the difference between groups, but subsequently the 2 groups began to diverge. Previous work has indicated that diazacon blocks conversion of desmosterol to cholesterol (Dietert and Scallen 1969, Emmons et al. 1982). Desmosterol is usually only found at low levels; hence, elevated desmosterol in our treated birds was also evidence of a weak treatment effect at this dose. The small reduction in cholesterol in the treated group at $9 \mathrm{mg} / \mathrm{kg}$ was 
Table 1. Behavior of captive rose-ringed parakeets following dosing with water (control, $n=11$ pairs) or $18 \mathrm{mg} / \mathrm{kg}$ diazacon (treated, $n=12$ pairs) for 10 days (trial 3), Yorkshire, United Kingdom, February-June 2008. We observed birds for 30 minutes for one morning (close to sunrise) and one afternoon (close to sunset) every 2 weeks between treatment and completion of first clutch. Data are mean percentage of observations for each activity.

\begin{tabular}{|c|c|c|c|c|c|c|c|c|}
\hline \multirow[b]{2}{*}{ Behavior } & \multicolumn{4}{|c|}{ Control } & \multicolumn{4}{|c|}{ Treated } \\
\hline & $\mathrm{M}(n=11)$ & M SE & $\mathrm{F}(n=11)$ & F SE & $\mathrm{M}(n=12)$ & M SE & $\mathrm{F}(n=12)$ & F SE \\
\hline Perching (i.e., on perch, branch, or aviary sides) & 63.1 & 4.7 & 52.0 & 6.3 & 58.0 & 3.4 & 44.8 & 5.4 \\
\hline Sleeping on perch or branch & 3.6 & 1.3 & 0.7 & 0.5 & 8.7 & 2.2 & 10.4 & 4.2 \\
\hline Maintenance (e.g., preening) & 6.5 & 0.7 & 4.2 & 0.9 & 8.5 & 1.6 & 3.2 & 0.9 \\
\hline Feeding on fruit or from feed tray & 7.0 & 1.4 & 3.8 & 1.1 & 7.4 & 2.0 & 3.7 & 1.0 \\
\hline Courtship and reproduction (e.g., allopreening, copulation) & 2.9 & 0.5 & 2.5 & 0.6 & 4.9 & 1.1 & 4.3 & 0.8 \\
\hline Nesting (i.e., investigating or inside nest box) & 4.6 & 2.1 & 28.8 & 5.3 & 2.5 & 1.4 & 25.4 & 5.9 \\
\hline Other activities (e.g., flying, walking) & 4.6 & 1.2 & 1.4 & 0.6 & 3.5 & 0.7 & 2.3 & 0.5 \\
\hline
\end{tabular}

considered unlikely to suppress reproduction, because a previous trial with monk parakeets estimated that a reduction of $50 \%$ would be required to affect fertility (Yoder et al. 2007). Following dosing with $18 \mathrm{mg} / \mathrm{kg}$ for 10 days, we observed a reduction in cholesterol of $>50 \%$, and again this appeared to be greatest at day 29. Although there was a difference between the groups, we also observed a cholesterol reduction in control birds during the trial, suggesting that another mechanism was acting. There was no interaction between treatment group and time; hence, this uncontrolled effect was acting equally on both groups, and was most likely due to underlying, seasonal changes in cholesterol levels. We conducted trial 2 during autumn when birds are not reproductively active and, hence, demand for cholesterol as a hormone precursor is reduced during this time. The subsequent recovery of cholesterol levels in control birds toward the end of trial 2 coincides with the start of the breeding season in early January, when demand for cholesterol begins to increase. This does suggest, however, that although there was an obvious (a)

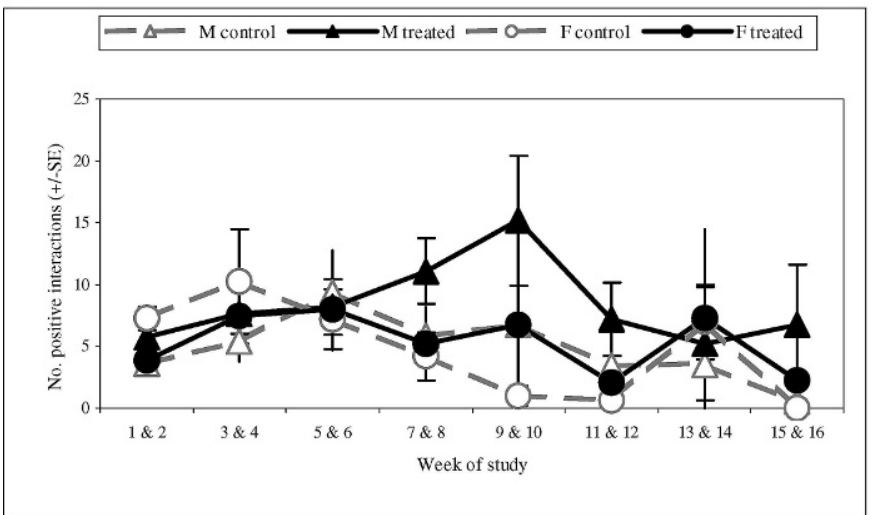

(c)

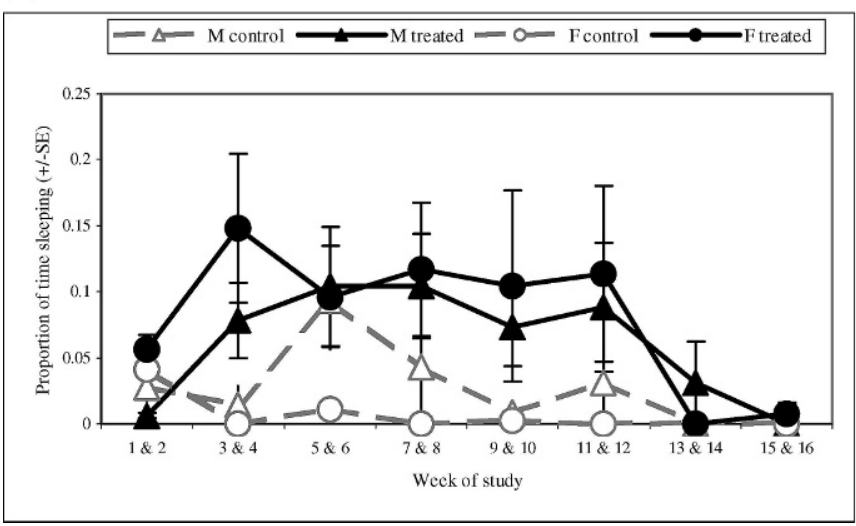

(b)

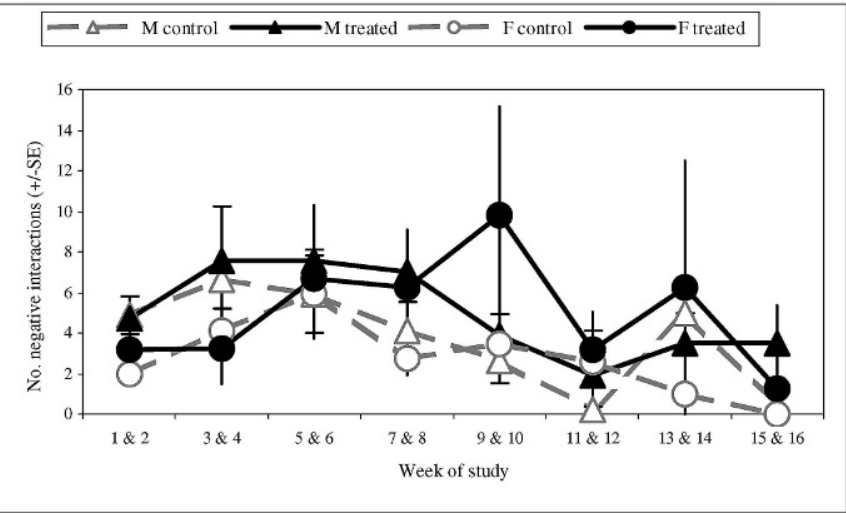

(d)

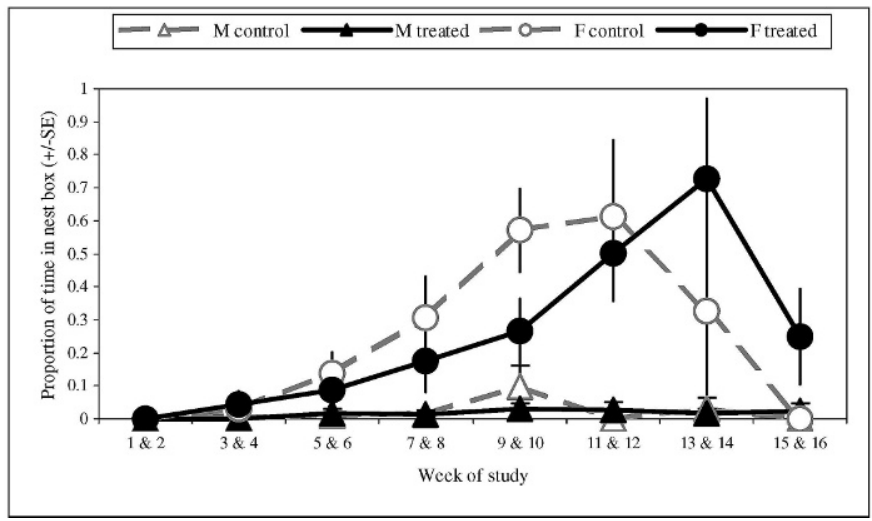

Figure 5. Rose-ringed parakeet behavior following dosing with water (control, $n=11$ pairs) or $18 \mathrm{mg} / \mathrm{kg}$ diazacon (treated, $n=12$ pairs) for 10 days (trial 3), Yorkshire, United Kingdom, February-June 2008. Panels a and b show the number of positive (a) and negative (b) interactions between birds. Panels c and $\mathrm{d}$ show proportion of time we observed birds sleeping (c) or in the nest box (d). We observed birds for 30 minutes one morning (close to sunrise) and one afternoon (close to sunset) every 2 weeks between treatment and completion of first clutch. 
treatment effect; reduction in cholesterol observed in the treated group was in part due to seasonal cycles.

Nevertheless, the reproductive study clearly showed that a dose of $18 \mathrm{mg} / \mathrm{kg}$ diazacon for 10 days reduced fertility in rose-ringed parakeets, because egg fertility rates were reduced by $54.2 \%$ for the first clutch and $66.5 \%$ for the second, compared to control birds. Number of fertile eggs produced by control birds was similar to the colony average for the previous year (Lambert et al. 2009). Interestingly, although the proportion of fertile eggs laid by treated birds was lower, they continued to lay nearly as many eggs as controls, suggesting that diazacon may have compromised the ability of male birds to fertilize eggs, potentially through reduction of sperm count or viability. The length of spermatogenesis for most species is $\geq 60$ days; hence, we would not expect any reduction in male fertility to be fully expressed until around 9 weeks after dosing, with recovery of fertility lagging behind recovery of cholesterol levels by a similar duration. The likely delay in recovery of fertility following recovery of cholesterol could explain why the treatment effect appeared greater for the second clutch when, according to the data from trial 2, cholesterol levels should have largely recovered to pretreatment levels. However, it is not possible to confirm this as the mode of action in this species without further study, including detailed analysis of reproductive hormones in both sexes.

Because of the delayed mode of action, dosing for 10 days at $18 \mathrm{mg} / \mathrm{kg}$ was sufficient to reduce fertility for the length of the breeding season, even when second clutches were produced. However, it is unlikely that treated birds would produce second clutches if the first was not removed, because second clutches are not usually produced by freeliving populations unless the first clutch is entirely lost (Lamba 1966). Production of infertile eggs by treated birds may be advantageous, in that birds would attempt to incubate the first clutch and, depending on how long they continued to incubate, would probably not re-lay. We observed females incubating clutches without fertile eggs for $\geq 46$ days and possibly up to 60 days before the eggs were abandoned or ejected from the nest box, up to 3 times the normal incubation period of 19-24 days (Lamba 1966, Simwat and Sidhu 1973, Shivanarayan et al. 1981). This is consistent with other species that are known to incubate infertile eggs for 2-3 times the normal period before finally deserting them (Winkler 2004). We also observed a delay in initiation of breeding in treated birds and a delay of about 2 weeks in nesting activity relative to controls. In Europe, rose-ringed parakeets potentially disadvantage native cavitynesting species through early occupation of nest sites (Lever 2005); thus, delayed breeding in treated parakeet populations may help to reduce this problem.

Following dosing with $18 \mathrm{mg} / \mathrm{kg}$ in the laboratory, we observed a temporary elevation in food intake in treated birds, although it did not appear to have any negative welfare consequences. The increased intake was small (approx. 1-2 g/bird/day) so it is unlikely that treated freeliving populations would be more inclined to deprive other species of food resources or damage substantially more crops. In the reproductive trial, diazacon appeared to have a transitory effect on behavior of the birds, most noticeably on proportion of time spent sleeping. We recorded treated birds, especially females, as spending more time sleeping than did control birds. This difference declined toward the end of our study, coinciding with an increase in reproductive activity from treated birds. The increased time spent sleeping could be an indication of lower reproductive hormone levels (and, hence, less motivation to reproduce) in treated birds during the early stages of the trial, but it would be difficult to confirm without further investigation. Furthermore, log-transformation of this data, although necessary for our analysis techniques, potentially obscures subtle effects through the loss of zeros from the data. Accordingly it should be noted that we examined gross changes in behavior of treated birds relative to control birds, and detailed analysis of behavior would require further study.

For field use against monk parakeets, Yoder et al. (2007) recommended a target dose of $<50 \mathrm{mg} / \mathrm{kg}$ to avoid potential side effects. In free-feeding trials, monk parakeets consumed on average $17 \mathrm{mg} / \mathrm{kg}$ and produced no hatchlings compared to $1.1( \pm 0.6)$ eggs/clutch in a control group (Yoder et al. 2007). In our study, using a dose of up to $18 \mathrm{mg} / \mathrm{kg}$, we observed no obvious signs of distress or ill health. Six birds died during our study, half of which were controls and the other half treated, which suggests that the deaths were not treatment-related. Furthermore, results of postmortem examinations did not suggest any link between these deaths and diazacon. Results from this trial are sufficiently encouraging to conclude that at the dose levels we used, diazacon has potential for reducing fertility levels in roseringed parakeets without major side effects. Our 2 dosage trials differed in both dose level and duration; hence, it is not possible to determine how much of the difference in results was driven by dosage or length of exposure. Further refinements may be possible by investigating the effect of dosing with $9 \mathrm{mg} / \mathrm{kg}$ for 10 days or $18 \mathrm{mg} / \mathrm{kg}$ for 5 days, but unfortunately this was not possible within the timeframe of our study. Of course, in addition to considering potential welfare effects on the target species, future work should seek to investigate options for formulation and delivery that mitigate any potential effect on other species. In field trials against wild populations of red-winged blackbirds (Agelaius phoeniceus) and common grackles (Quiscalus quiscula), Fringer and Granett (1970) noted that unless feeding continued for 10 days until a plateau was reached, diazacon was not effective. Fringer and Granett (1970) suggested that because of the need for a sustained feeding period, and the temporary nature of the treatment effect, the risk to nontarget animals, including raptors feeding on target birds, was low. Of course the importance of confirming this suggestion should not be understated; carefully monitored pilot trials should confirm that nontarget populations are not at risk before wider use against rose-ringed parakeets in the field. A potential solution to mitigating any possible risks lies in development of a species-specific feeding system to limit exposure only to rose-ringed parakeets, which 
appear to have few predators (potential secondary nontarget species) outside their native range. In the United Kingdom, rose-ringed parakeets are largely able to avoid predation (Pithon and Dytham 1999). It also remains to be seen whether reductions in fertility that we achieved would be sufficient to impact population levels in the wild. Little is known about the ecology of rose-ringed parakeets outside their native range, and this has so far hindered development of spatially explicit population models that could determine the level of fertility control required for significant population-level effects. However, recent work suggests that in parts of their introduced range, reproductive output of rose-ringed parakeets is lower than in the native range (Shwartz et al. 2009). Hence it is possible that contraception of a low proportion of the population could have a substantial impact on population levels.

As with many introduced species, particularly one that has a predominantly urban distribution, management issues surrounding rose-ringed parakeets tend to be controversial, especially in relation to any suggestion of large-scale lethal control. Contraception potentially offers a nonlethal alternative (or supplement) to more traditional control methods, although applying the technique still faces considerable challenges. If these challenges can be resolved, fertility control could become a useful tool for managing free-living populations of rose-ringed parakeets where lethal control is undesirable or not possible, potentially helping to halt or reverse expansion of this ecologically and economically important invasive species.

\section{MANAGEMENT IMPLICATIONS}

Rose-ringed parakeet populations are established in several countries outside their native range and are predicted to continue expanding. Management of populations is controversial, with opinions divided on whether populations should be eradicated entirely, allowed to expand, or limited near current levels. Fertility control potentially offers a middle-ground solution for containment rather than control, and from our evaluations, diazacon appears to be a suitable contraceptive with no serious side effects at the dose levels we used. However, further evaluations are necessary, including development of suitable formulation and application methods, and subsequent pilot field trials, before wide-scale use of diazacon for managing free-living rose-ringed parakeet populations is possible.

\section{ACKNOWLEDGMENTS}

This work was supported by Defra project WM0406. We thank J. Bell, M. Brash, A. Forsyth, G. Watola, J. Coats, L. Richardson, K. Storer, and members of the Fera ASIST team, including L. Berry, M. Gale, N. Cook, and K. Hunter, for valuable assistance. We also thank R. BrandHardy and 2 anonymous referees for helpful comments on the original manuscript.

\section{LITERATURE CITED}

Altmann, J. 1974. Observational study of behavior: sampling methods. Behaviour 49:227-267.
Avery, M. L., C. A. Yoder, and E. A. Tillman. 2008. Diazacon inhibits reproduction in invasive monk parakeet populations. Journal of Wildlife Management 72:1449-1452.

Babu, R. S., and T. S. Muthukrishnan. 1987. Studies on the damage by Psittacula krameri (Scopoli) and Passer domesticus (Linnaeus) on certain crops. Tropical Pest Management 33:367-369.

Brown, H. K., and R. A. Kempton. 1994. The application of REML in clinical trials. Statistics in Medicine 13:1601-1617.

Dietert, S. E., and T. J. Scallen. 1969. An ultrastructural and biochemical study of the effects of three inhibitors of cholesterol biosynthesis upon murine adrenal gland and testis. Journal of Cell Biology 40:44-60.

Emmons, G. T., E. R. Rosenblum, J. N. Peace, J. M. Malloy, D. L. Doerfler, I. R. McManus, and I. M. Campbell. 1982. Effects of 20,25diazacholesterol on cholesterol synthesis in cultured chick muscle cells: a radiogas chromatographic and mass spectrometric study of the postsqualene sector. Biomedical Mass Spectrometry 9:278-285.

Fringer, R. C., and P. Granett. 1970. The effects of Ornitrol on wild populations of red-winged blackbirds and grackles. Bird Control Seminar 5:163-176.

Johnston, J. J., M. J. Goodall, C. A. Yoder, C. A. Furcolow, D. A. Goldade, B. A. Kimball, and L. A. Miller. 2003. Desmosterol: a biomarker for the efficient development of 20,25-diazacholesterol as a contraceptive for pest wildlife. Journal of Agricultural and Food Chemistry 51: 140-145.

Lacombe, D., P. Matton, and A. Cyr. 1987. Effect of Ornitrol on spermatogenesis in red-winged blackbirds. Journal of Wildlife Management 51:596-601.

Lamba, B. S. 1966. Nidification of some common Indian birds. 10. The rose-ringed parakeet, Psittacula krameri Scopoli. Proceedings of the Zoological Society, Calcutta 19:77-85.

Lambert, M. S., G. Massei, J. Bell, L. Berry, C. Haigh, and D. P. Cowan. 2009. Reproductive success of rose-ringed parakeets Psittacula krameri in a captive UK population. Pest Management Science 65:1215-1218.

Lever, C. 2005. Naturalised birds of the world. T. \& A.D. Poyser, London, United Kingdom.

Marshall, K., R. White, and A. Fischer. 2007. Conflicts between humans over wildlife management: on the diversity of stakeholder attitudes and implications for conflict management. Biodiversity and Conservation 16:3129-3146.

Messmer, T. A., L. Cornicelli, D. J. Decker, and D. G. Hewitt. 1997. Stakeholder acceptance of urban deer management techniques. Wildlife Society Bulletin 25:360-366.

Miller, L. A., and K. A. Fagerstone. 2000. Induced infertility as a wildlife management tool. Vertebrate Pest Conference 19:160-168.

Patel, J. L., M. C. Patel, B. M. Parasharya, and A. M. Patel. 2002. Management of fruit damage by parakeets (Psittacula krameri) in pomegranate (Punica granatum L.). Annals of Arid Zone 41:207-209.

Pithon, J. A., and C. Dytham. 1999. Census of the British ring-necked parakeet Psittacula krameri population by simultaneous counts of roosts. Bird Study 46:112-115.

Shivanarayan, N., K. S. Babu, and M. H. Ali. 1981. Breeding biology of rose-ringed parakeet Psittacula krameri at Maruteru. Pavo 19: 92-96.

Shwartz, A., D. Strubbe, C. J. Butler, E. Matthysen, and S. Kark. 2009. The effect of enemy-release and climate conditions on invasive birds: a regional test using the rose-ringed parakeet (Psittacula krameri) as a case study. Diversity and Distributions 15:310-318.

Simwat, G. S., and A. S. Sidhu. 1973. Nidification of rose-ringed parakeet, Psittacula krameri (Scopoli), in Punjab. Indian Journal of Agricultural Sciences 43:648-652.

Stout, R. J., B. A. Knuth, and P. D. Curtis. 1997. Preferences of suburban landowners for deer management techniques: a step towards better communication. Wildlife Society Bulletin 25:348-359.

Strubbe, D., and E. Matthysen. 2007. Invasive ring-necked parakeets Psittacula krameri in Belgium: habitat selection and impact on native birds. Ecography 30:578-588.

Sturtevant, J., and B. C. Wentworth. 1970. Effect on acceptability and fecundity to pigeons of coating SC 12937 bait with zein or ethocel. Journal of Wildlife Management 34:776-782.

Winkler, D. W. 2004. Nests, eggs and young: breeding biology of birds Pages 8.1-8.152 in S. Podulka, R. Rohrbaugh, Jr., and R. Bonney, editors. Handbook of bird biology. The Cornell Laboratory of 
Ornithology in Association with Princeton University Press, New York, New York, USA.

Wofford, J. E., and W. H. Elder. 1967. Field trials of the chemosterilant SC-12937 in feral pigeon control. Journal of Wildlife Management 31:507-515

Yoder, C. A., W. F. Andelt, L. A. Miller, J. J. Johnston, and M. J. Goodall. 2004. Effectiveness of twenty, twenty-five diazacholesterol, avian gonadotropin-releasing hormone, and chicken riboflavin carrier protein for inhibiting reproduction in Coturnix quail. Poultry Science 83:234244.

Yoder, C. A., M. L. Avery, K. L. Keacher, and E. A. Tillman. 2007. Use of DiazaCon (TM) as a reproductive inhibitor for monk parakeets (Myiopsitta monachus). Wildlife Research 34:8-13.

Associate Editor: Ganey. 